\title{
Desconstruir para Problematizar Matrizes Identitárias
}

Deconstruct to Problematize Identity Matrices

Deconstruir para Problematizar las matrices de identidad

\section{Mériti de Souza \&}

Fabíola Langaro

Universidade Federal de Santa Catarina
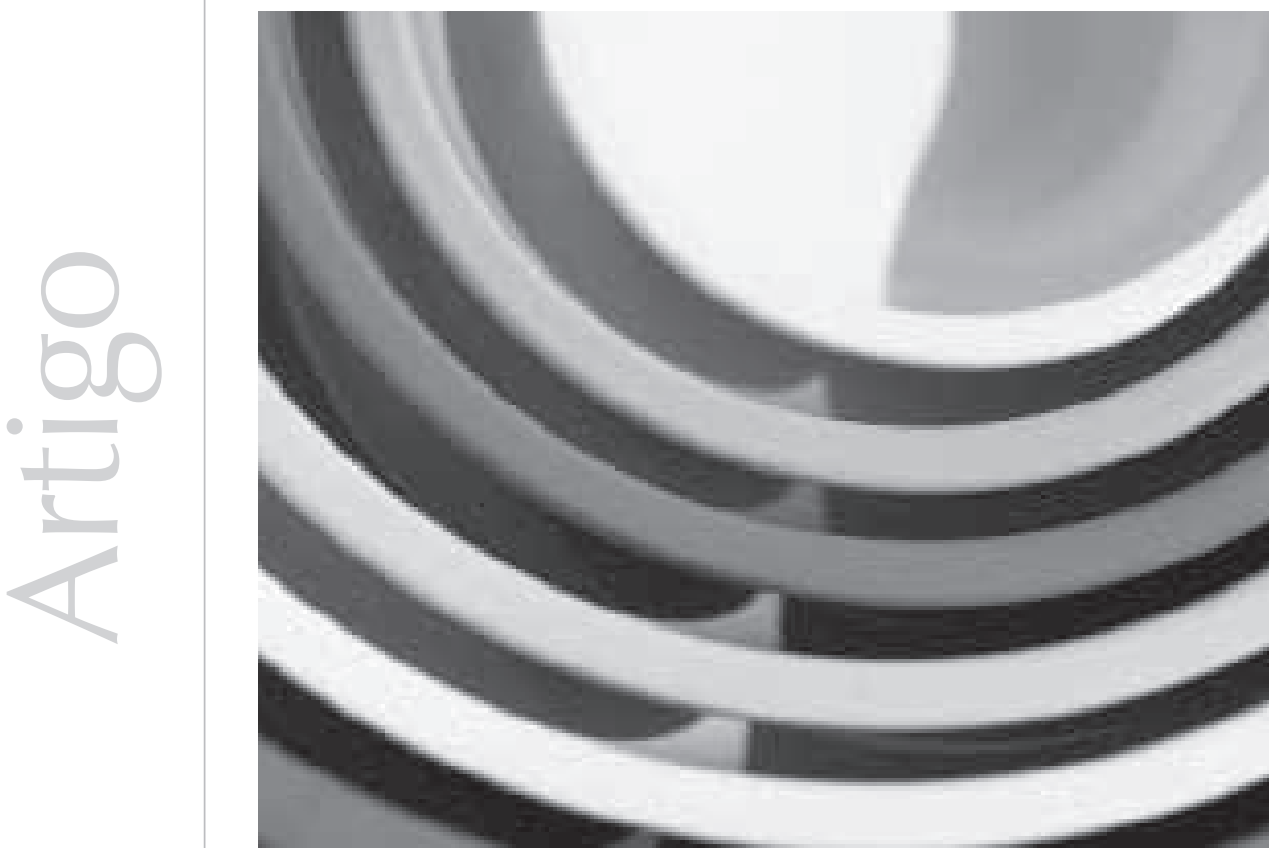
Resumo: A rede social contemporânea encontra-se marcada pela construção e pela disseminação de matrizes identitárias configuradas por binarismos, hierarquias e atribuição de específicos sentidos às configurações subjetivas. Com este estudo, objetiva-se problematizar as possibilidades de desconstrução dessas matrizes concomitantemente ao deslocamento de sentidos a elas agregados. Os aportes teóricos de Butler e Derrida possibilitam compreender que as referências identitárias fundamentadas na tradição filosófica ocidental da metafísica da presença engendram o enunciado da subjetividade e os sentidos agregados ao masculino e ao feminino. A construção do enunciado do gênero como identidade possibilita aos sujeitos se reconhecerem em referência às suas práticas de sexualidade e à heteronormatividade, que estabelece tanto as oposições masculino/feminino, heterossexual/homossexual quanto a hierarquia entre esses pares. Entende-se que o deslocamento dos sentidos atribuídos aos pares binários pode ocorrer a partir da desconstrução dos pressupostos que organizam as matrizes identitárias dominantes na rede social.

Palavras-chave: Derrida. Jacques. Metafísica. Identidade. Psicologia.

Abstract: The contemporary social network is marked by the construction and dissemination of identity matrices set by binaries, hierarchies and the assigning of specific meanings to subjective configurations. This study aims to discuss the possibilities of avoiding these matrices concomitantly to the displacement of the meanings they aggregate. The theoretical contributions of Butler and Derrida make possible to understand that identity reference based on the western philosophical tradition of metaphysics of presence engendered the utterance of subjectivity and the sense assigned to male and female. The construction of gender as a statement of identity enables individuals to recognize themselves in reference to their practice of sexuality and heterosexuality that establishes both the oppositions male/female, heterosexual/homosexual as the hierarchy between these pairs. It is understood that shifting meanings attributed to the binary pairs can take place from the deconstruction of the assumptions that organize the identity matrices in the dominant social network. Keywords: Derrida. Jacques. Metaphysics. Identity. Psychology.

Resumen: La red social contemporánea se encuentra marcada por la construcción y diseminación de matrices de identidad configuradas por binarismos, jerarquías y atribución de específicos sentidos a las configuraciones subjetivas. Con este estudio se tiene como objetivo demostrar los problemas de las posibilidades de destrucción de esas matrices concomitantemente al desplazamiento de sentidos a ellas agregados. Los aportes teóricos de Butler y Derrida posibilitan comprender que las referencias de identidad fundamentadas en la tradición filosófica occidental de la metafísica de la presencia engendran el enunciado de la subjetividad y los sentidos agregados a lo masculino y a lo femenino. La construcción del enunciado del género como identidad posibilita a los sujetos reconocerse en referencia a sus prácticas de sexualidad y la heteronormatividad que establece tanto las oposiciones masculino/femenino, heterosexual/homosexual, como la jerarquía entre esos pares. Se entiendo que el desplazamiento de los sentidos atribuidos a los pares binarios puede suceder a partir de la destrucción de los presupuestos que organizan las matrices de identidad dominantes en la red social.

Palabras clave: Derrida. Jacques. Metafísica. Identidad. Psicología.

No decorrer dos últimos anos, realizamos atendimentos em contextos formais e não formais de escolarização e saúde e observamos a presença constante de discursos que associam as marcas da classe social, da etnia e da configuração de gênero, dentre outras, à condição emocional e cognitiva das pessoas que as carregam. Ato contínuo foi a constatação que esses discursos alimentavam a rede simbólica coletiva e singular que produz modos de subjetivar que tanto qualificam quanto desqualificam a priori aqueles que se constituem a partir desses padrões identitários calcados em marcas socioeconômicas, generalizadas, étnicas, dentre outros. Concomitantemente, esse processo induz inúmeros profissionais, dentre eles profissionais da saúde e da educação, a elaborarem a concepção de que matrizes identitárias forjadas segundo padrões culturais e subjetivos idealizados e normatizados encontram-se amalgamadas à constituição subjetiva. Em outras palavras, referências culturais e históricas estabelecem modelos de competência social, psicológica, cognitiva e moral associados a configurações identitárias e, dessa forma, aqueles que correspondem a esses modelos são idealizados a priori, bem como aqueles que não correspondem são desqualificados a priori. 
...temos uma modalidade de organização econômica, do conhecimento e da subjetividade que serve de base para a crescente expansão do modo de vida liberal e capitalista levada ao extremo nos processos de colonização e de globalização (Sousa Santos, 2002, 2003).
A partir desse cenário, podemos localizar o modo de subjetivar predominante na modernidade ocidental calcado na crença de que a constituição subjetiva se encontra subsumida à consciência conformada como totalidade e razão. Assim, pessoas configuradas pela subjetividade moderna se acreditam constituídas por uma consciência que tanto abarca plenamente a subjetividade quanto oferece acesso total à realidade e ao controle sobre si e sobre o outro. Também podemos apontar a questão de que o modo de produzir conhecimento na modernidade, centrado na dissociação entre sujeito e objeto, mente e corpo, razão e paixão, engendra o sujeito epistêmico do cogito, assumindo o universal, o cálculo e o logos, bem como escamoteia o pathos, o singular e os limites da consciência. Esses parâmetros epistemológicos e ontológicos operam a partir da sua associação a axiomas configurados como verdade e universalidade, o que possibilita a sua disseminação na rede social, cultural, econômica e subjetiva (Foucault, 1999; Morin, 2005; Derrida, 2008, 2009; Bachelard, 1996). Dessa forma, temos uma modalidade de organização econômica, do conhecimento e da subjetividade que serve de base para a crescente expansão do modo de vida liberal e capitalista levada ao extremo nos processos de colonização e de globalização (Sousa Santos, 2002, 2003).

Pensar sobre o projeto moderno demanda relevar que esse processo comportou diversas vertentes e que a sua implantação, no decorrer dos últimos séculos, implicou mudanças nas concepções iniciais. Assim, o movimento iluminista e o liberal apresentam diversos ideários que abarcam desde perspectivas políticas, filosóficas até econômicas. Marcam essas perspectivas as concepções do homem como sujeito racional, os ideais do contrato como regulador social, a delimitação do público e do privado, a implantação da economia de mercado e as premissas da liberdade e da igualdade (Bobbio, Matteucci,
\& Pasquino, 1986; Bobbio, 1986b; Burdeau, $s / d)$.

Por seu turno, a produção teórica e metodológica da Psicologia é orientada por diferentes concepções de constituição subjetiva e de realidade, sendo que a maioria dessas concepções acompanha o advento da modernidade. Um dos projetos da modernidade pontuado pelo iluminismo diz respeito à produção do sujeito da razão autônoma, concebido como apto a conhecer o real, a verdade, e a agir no plano ético orientado por esse conhecimento. Nessa tradição, a subjetividade constitui consciência reflexiva que se representa como unidade integrada e identitária, capaz de conhecer de forma plena a si mesma, ao mundo e de orientar-se pela razão controlando os afetos. No plano da organização do Estado, o ideal moderno postula a constituição do sujeito racional e ético associada ao exercício da cidadania, ou seja, a conquista da cidadania operaria um efeito subjetivo necessário à reorganização subjetiva e cognoscente (Souza, 2006).

A partir desse contexto, faz-se necessário problematizar as concepções de sujeito e de realidade no entrelace entre a tradição filosófica e a prática psicológica, social e política. Entretanto, a dificuldade em realizar esse trabalho e problematizar esse elo se encontra na tradição que acompanha o termo subjetividade, fruto da denominada filosofia do sujeito ou filosofia da consciência e, particularmente, na relação estabelecida entre o sujeito substantivado e a denominada potência para a ação. Segundo essa tradição, o agente ativo, no caso o sujeito substantivado, atuaria de forma direta, linear e causal sobre o contexto e os objetos passivos, modificando-os. Outra questão crucial diz respeito à relação estabelecida entre o singular e o universal, considerando a queda do singular na maior parte das teorias e práticas, tanto psicológicas quanto outras, que 
predominam na seara contemporânea. Outra questão, ainda, se reporta à leitura acerca da temporalidade que também acompanha a tradição que privilegia o conceito do linear e do contínuo. Não obstante apontarmos essas questões como fundamentais ao trabalho de problematizar o elo teórico e prático que associa a constituição das subjetividades, da realidade, do conhecimento e do tempo, a extensão e a amplitude do problema demandam a escolha de um tema. Dessa forma, vamos trabalhar com a assunção da matriz identitária como correlata à verdade e ao universal que escamoteia o singular, pois esse ponto repercute de forma marcante nas teorias e nas práticas psicológicas e sociais.

Neste trabalho teórico, nosso objetivo é o de problematizar a universalidade e a verdade sobrepostas às matrizes identitárias nas suas relações com o conhecer e o subjetivar. Interessa oferecer inteligibilidade às experiências coletivas e singulares que rompem modelos tradicionais de configuração subjetiva, social e política bem como problematizar as relações estabelecidas entre essas configurações e os corpos e desejos configurados para além dos pressupostos modernos, racionais, universais e heteronormativos. Espera-se contribuir para a construção de intervenções psicológicas e políticas que contemplem a singularidade e a constituição subjetiva que não se sobreponham a modelos e a normas definidos a priori.

\section{Contextos identitários, hierárquicos e modernidade}

Vivemos em uma sociedade ocidental moderna. Sobre esse fato, compartilhado por nós que lemos este texto, parece haver algumas concordâncias entre certos autores: conceitos como individualidade, interioridade, soberania, sujeito, capitalismo, privacidade e racionalidade adquiriram importante status e atravessam as relações humanas na contemporaneidade (Chauí, 2000; Foucault, 1990, 1999; Derrida, 2001, 2007). Principalmente com relação às ciências psi, conceitos como os de sujeito, interioridade, racionalidade e privacidade ganharam aspectos de verdades, que nem sempre são suficientemente problematizados para serem compreendidos como possuidores de demarcações históricas.

Do ponto de vista cronológico, podemos dizer que a epistemologia moderna, configurada em Teoria do Conhecimento, tornou-se disciplina específica em meados do século XVII. Com ela, começou a surgir e a ganhar hegemonia, entre outras modalidades de conhecimento, o pensamento científico comprometido com o universal e os questionamentos relacionados às condições de possibilidade para que a verdade fosse alcançada.

Algumas ressalvas quanto ao nascimento da ciência, no entanto, são feitas por Foucault (1999). Para ele, nos séculos XVII e XVIII, coexistiam, pelo menos, outras duas epistemes: uma clássica, operando segundo o princípio da representação, e uma renascentista que, com algumas mudanças, opera a partir da exegese e da interpretação da verdade. A episteme moderna surge, então, rompendo essas duas anteriores, objetivando a busca pela verdade, sendo esse o ideal da modernidade. Essa preocupação da ciência é um ponto fundamental para compreender a ruptura entre as epistemes renascentista, clássica e moderna: nas duas epistemes precedentes à moderna, ou a Filosofia não se preocupava com a possibilidade de conhecer a verdade, visto que, para os gregos, conforme destaca Chauí (2000, p. 143), ela era "concebida como presença e manifestação do verdadeiro aos nossos sentidos ou ao nosso intelecto, isto é, como presença do Ser à nossa experiência sensível ou ao puro pensamento", ou, como na episteme renascentista, afirmava que ela só poderia ser dada por Deus. 
1 Segundo Chauí (2000, pp.72-73) o princípio da identidade, o da não contradição, o do terceiroexcluído e o da razão suficiente (princípio da causalidade) constituem os fundamentos do conhecimento moderno.
Mas quais eram as condições históricas da época que tornaram possível essa mudança na busca do saber e da verdade? Se, momentos antes do surgimento da episteme moderna, Deus estava no centro do mundo, o que tornou possível ao homem ocupar o lugar de destaque no pensamento humano? Podemos, aqui, citar marcos dessa transformação que se operou lenta e gradativamente: 0 esgotamento do mundo feudal (séculos XV e XVI), a Reforma e a Contrarreforma da Igreja Católica (século XVI), o Iluminismo (século XVII), a Revolução Industrial e a Revolução Francesa do século XVIII. Todo esse cenário possibilitou o surgimento da ciência moderna. Além disso, o contexto de mudanças socioeconômicas provocadas pela Revolução Francesa e pela Revolução Industrial, em meio aos ideais iluministas e românticos do século XVIII, permitiu o enunciado do sujeito - o ideal do homem moderno. Esse enunciado era, assim, social, político e econômico, na medida em que observava os ideais do liberalismo e do individualismo.

Considerando que a episteme moderna é um sistema de pensamento que ganhou hegemonia entre outros, destaca-se que ela é caracterizada por concepções que marcam sua ruptura com sistemas de pensamentos anteriores, entre eles: 1) a separação da fé e da razão, 2) a busca da explicação sobre como a alma-consciência poderia ter acesso ao conhecimento e 3) a tarefa de explicar como a razão e o pensamento podem tornarse mais fortes do que a vontade e controlá-la para evitar o erro (Chauí, 2000). Portanto, o pensamento científico moderno é regido pelo princípio da Razão, que obedece a certas regras ou leis fundamentais ${ }^{1}$, e que coloca o Homem no centro do pensamento vigente, como aquele a quem é dada a possibilidade de conhecer e alcançar a verdade - uma verdade universal, generalizável, que reside no objeto como essência.
O modelo de ciência moderno nascente se desenvolveu principalmente no domínio das ciências naturais, visto que há uma separação entre o homem - ativo e capaz de conhecimento - e a natureza - passiva, que deve ser desvendada e dominada. E foi também sob a égide dessa primazia da objetividade, da razão, da comprovação, do paradigma universal e do positivismo das ciências naturais que, a partir do século XIX, se desenvolveram as ciências humanas, achandose, entre suas disciplinas, a Psicologia.

Desse modo, ao receber o reconhecimento como ciência, na passagem do século XIX para o século XX, a Psicologia caracterizava-se pelo positivismo, pela busca da compreensão de um sujeito universal e de verdades gerais, ou seja, estava imbuída do pensamento hegemônico da episteme moderna. Nesse sentido, Figueiredo (1992), aponta que o século XIX se caracterizava pelo apogeu do liberalismo, do romantismo e do regime disciplinar. Assim, destaca esse autor que "o espaço psicológico, tal como hoje o conhecemos, nasceu e vive precisamente da articulação conflitiva daquelas três formas de pensar e praticar a vida em sociedade" (p.131).

É nesse contexto que a Psicologia produziu a invenção do psicológico e da subjetividade como modalidade de constituição psíquica, visto que comprometida com a soberania do sujeito da modernidade. É principalmente a partir do século XIX que o homem é compreendido como sujeito autônomo, constituído pela razão, produto da vontade e, ainda, como aquele capaz de criar as condições que Ihe garantiriam uma estabilidade psicológica possível e desejada.

Nesse sentido, conforme aponta Figueiredo (1992), houve um processo de interiorização do eu concomitante ao movimento social, econômico e político de demarcar o espaço público e o espaço privado, fazendo com 
que a subjetividade ficasse limitada ao âmbito privado. Isso foi possível, em grande parte, pela ascensão dos ideais burgueses - de família, de produção econômica e de organização da vida social - provenientes da Revolução Industrial. Assim, na modernidade, o que o sujeito faz, pensa e sente é associado à ordem do individual, íntimo, interior e privado, e configura a experiência da subjetividade privatizada.

É possível asseverar que esse cenário promove e cauciona premissas que delineiam a psicologia das identidades e a subjetividade configurada como sujeito. Assim, perguntamos: quais modos de subjetivação elas promovem e possibilitam? Silva, em discussão sobre processos de produção da identidade e da diferença, destaca a necessidade de representação da identidade como forma de significar sua construção e significação social. Para o autor, a representação, como "marca ou traço visível, exterior", é o que permite enunciar que "essa é a identidade, a identidade é isso" (2008, p. 91). Nessa perspectiva, Pinto assinala que a identidade é então considerada uma unidade estável a quem cabe uma representatividade, sendo uma construção exigida "pelos ritos convencionais que postulam o sujeito de maneira a garantir a possibilidade do 'nós' a partir da significação prévia do 'eu'” (2007, p. 16).

Em que medida, contudo, é possível aplicar os enunciados apontados acima? Será possível, então, falar em identidade como uma estabilidade inerente ao sujeito? Seria a representação uma forma segura de dar significado a uma identidade ou seria ela uma forma de o sujeito organizar um discurso para, então, ser capaz de afirmar uma identidade?

A desconstrução derridiana e as matrizes de sexo e gênero

Para Derrida $(2001,2008)$, a sociedade ocidental e moderna da qual fazemos parte tem como base um sistema de pensamento calcado na metafísica da presença, em que a produção do conhecimento está fundamentada nos princípios do universal e da substância. Para o autor (2001, p. 231),

a história da metafísica, como a história do Ocidente, seria a história dessas metáforas e dessas metonímias (os diferentes nomes que utilizamos para nos referir a um centro ou fundamento estável a partir do qual possamos pensar a totalidade de uma estrutura ou mesmo da realidade em geral). A sua forma matricial seria (...) a determinação do ser como presença em todos os sentidos dessa palavra. Poderse-ia mostrar que todos os nomes do fundamento, do princípio, ou do centro, sempre designaram o invariante de uma presença (eidos, arquê, telos, energeia, ousia (essência, existência, substância, sujeito) alehteia, transcendentalidade, consciência, Deus, homem, etc.)

Segundo o Derrida (2008, p. 4),
"a história da metafísica que, apesar de todas as diferenças, e não apenas de Platão a Hegel (...), sempre atribuiu ao logos a origem da verdade em geral", subsume um movimento de elogio do logos produzindo um sistema de pensamento "solidário com a determinação do ser do ente como presença" (p. 15)

Esse movimento que predomina na sociedade ocidental recebe a denominação de logocentrismo, e pressupõe a razão plena e total como o ponto de referência a partir do qual ocorreria a modalidade de subjetivação articulada ao sujeito.

Destaca-se que, na problematização realizada por Derrida (2008) sobre o projeto da Filosofia metafísica, está incluída a crítica à compreensão de que os sentidos estariam incrustados aos signos. Nessa lógica de pensamento ocidental tradicional, o signo seria composto pelo significante e pelo significado, em que o significante equivaleria à camada sonora do signo linguístico, e o significado, à camada abstrata, o que implica 
a oposição entre significante e significado, sendo o significante exterior, e o significado, interior ao signo. A partir disso, poder-se-ia inferir que, a cada significante, caberia um único significado, exterior e contingencial, derivado e representativo do significante.

Esse significado do signo, por sua vez, guardaria proximidade ao logos como phoné, ou seja, preservaria relação direta e privilegiada com a presença plena. Seria, portanto, "congênita a essa filosofia" (Derrida, 2009, p. 413) a organização do pensamento a partir de sistema de oposições, em que opera a idéia de que pares binários se encontram separados e hierarquicamente colocados, estabelecendo todos os demais sentidos a partir da lógica de compreensão do signo como significante + significado. Segundo Derrida (2009, p. 413), "desde a oposição physis/nomos, physis/techné, chega até nós graças a toda uma cadeia histórica que opõe a 'natureza' à lei, à instituição, à arte, à técnica, mas também à liberdade, ao arbitrário, à história, à sociedade, ao espírito, etc".

Assim, a "grande época abrangida pela história da metafísica" (Derrida, 2008, p.15) está marcada pelo privilégio da razão e da fala como meios possíveis de atingir o ser como presença e substância. A ideia de que há, desse modo, um sentido original a ser buscado como essência ou fundamento envolve dizer que esse sentido assume um caráter de universalidade, ou seja, de verdade que é transparente em si mesma, mantendo sempre relação ao que seria "natural no homem" e que poderia ser acessado pela fala. Nas palavras de Continentino (2006, p. 58), "o desejo de verdade comanda o ocidente, desejo da palavra plena, que só se manifesta através do discurso falado, quando o sentido e a voz, o pensamento e a voz se dão numa relação supostamente sem resto". E é a partir das relações que se estabeleceram e se fixaram entre os pares natureza/cultura, por exemplo, que se preservam as características ditas universais dos sentidos que compõem a realidade.

É esse sistema filosófico que torna possível, então, criar associações e lógicas de pensamento em que conceitos como os de subjetividade, interioridade, identidade e consciência, por exemplo, coincidem. Assim, ao se falar em sujeito, a ele imediatamente se associariam as ideias de subjetividade, identidade, razão e cognoscência, entre outros.

De forma próxima a Derrida, Butler (2008) destaca que a crença na unidade ou identidade provém da tradição filosófica ocidental e moderna calcada na metafísica da presença. Essa tradição filosófica possibilita aos sujeitos se manifestarem como subjetividades substantivadas, ou seja, como sujeitos dotados de uma identidade que possui um núcleo estável, uma essência - talvez aquela mesma almejada pela ciência moderna positivista.

É aqui, neste ponto, que podemos então problematizar as intercessões entre os conceitos de matriz de pensamento e de matrizes identitárias. Especificamente com relação à matriz de pensamento moderno, ela engendra cenários sociais, econômicos e culturais peculiares, tendo se especializado em produzir subjetividades "que se acreditam constituídas por uma consciência que lhes oferece o pleno conhecimento sobre si e sobre o real" (Souza, 2007, p. 139). É a metafísica da presença como matriz do pensamento moderno, portanto, que cria condições de possibilidade ao enunciado do discurso que cada um de nós constrói a seu respeito, a respeito do outro e do contexto. É ela, ainda, que produz a representação unitária e linear sobre nossa subjetividade, sustentando concepções e práticas referentes à constituição do sujeito e das redes sociais (Souza, 2007, p. 140). 
Considerando que a lógica linear e causal subjaz ao pensamento moderno, é essa matriz que possibilita o enunciado da subjetividade que opera na compreensão das identidades de gênero, permitindo aos sujeitos se posicionarem em referência às suas práticas de sexualidade. É por meio dela que as pessoas se denominam, entre outras, masculino, feminino, homossexual, heterossexual, gay ou lésbica. Possivelmente, a principal intercessão entre as matrizes identitárias e as questões de gênero possa ser descrita como a pressuposição de que "uma pessoa é um gênero ou o é em virtude de seu sexo, de seu sentimento psíquico do eu, e das diferentes expressões desse eu psíquico, a mais notável delas sendo a do desejo sexual" (Butler, 2008, p. 44), presumindo uma "coerência ou unidade interna de qualquer dos gêneros" (p. 45).

É, assim, a mesma matriz de pensamento moderno que possibilita o sentimento da subjetividade concomitante à substantivação dos sujeitos que engendra a naturalização do pressuposto que cada pessoa nasce com um corpo sexuado, biológico, e que a partir dele constituirá um gênero associado a uma identidade, garantindo a coerência entre esse sexo biológico, o gênero construído na/pela cultura e o desejo sexual. Essa heterossexualidade como norma ou heteronormatividade seria, conforme aponta Butler (2008), a matriz de inteligibilidade hegemônica que pressupõe a produção de sujeitos marcados pela crença de que seu gênero e seu sexo anatômico correspondem a uma identidade, e que seu objeto de desejo se associa a pessoas de sexo e de gênero diferentes, partindo-se da ideia de complementaridade pela diferença.

Para a autora,

a coerência ou a unidade internas de qualquer dos gêneros, homem ou mulher, exige assim uma heterossexualidade estável e oposicional. Essa heterossexualidade institucional exige e produz, a um só tempo, a univocidade de cada um dos termos marcados pelo gênero que constituem o limite das possibilidades de gênero no interior do sistema de gênero binário oposicional. Essa concepção de gênero não só pressupõe uma relação causal entre sexo, gênero e desejo, mas sugere igualmente que o desejo reflete ou exprime o gênero, e que o gênero reflete ou exprime o desejo (Butler, 2008, p. 45)

Além dessa matriz a partir da qual os sujeitos constroem suas experiências em relação ao masculino e ao feminino, há, de acordo com Derrida e Roudinesco, 2004, um modo falogocêntrico de a sociedade ocidental representar o feminino tomando sempre como base o masculino, ou seja, pressupondo o falo como o centro e o ponto de referência a partir do qual ocorreria todo processo de subjetivação. Derrida destaca que o termo falogocentrismo foi elaborado

a partir de falocentrismo e logocentrismo, para designar o primado concedido de um lado pela filosofia ocidental ao logos platônico, e, de outro, pela psicanálise à simbólica greco-freudiana do Falo, segundo a qual não existiria senão uma libido (ou energia sexual) e que esta seria de essência masculina (Derrida \& Roudinesco, 2004, p. 36)

Em outras palavras, com o termo falogocêntrico, o autor pretendia dirigir sua crítica à primazia na tradição da Filosofia ocidental que constrói teorias e leituras acerca da realidade, do conhecimento e da constituição psíquica baseadas em referências falocêntricas e logocêntricas. Essas referências definem hierarquias e um modo binário de produzir oposições quando atribuem qualificações e sentidos aos pares de opostos que são designados pela rede social, econômica e cultural. O binarismo acompanha a rede de poder que predomina nas sociedades ocidentais e reforça essa rede através da linguagem que atribui específicos sentidos e valores às pessoas e aos objetos que compõem a realidade. Para Derrida 
(2008, 2009), quando são elaborados os pares de opostos, é atribuído um sentido específico a eles, e, ainda, quando se divulga a ideia de que esse sentido é verdadeiro, é possível encontrar um trabalho de hierarquia e de poder. Como exemplo, o conceito de masculino estabelece o feminino como seu oposto e, ainda, o masculino é vinculado ao racional, ao completo, à cultura, e o feminino, ao afeto, ao incompleto, à natureza.

Considerando que a matriz binária heterossexual da diferença sexual se converteu no modelo regulador da subjetividade, é ela que possibilita às pessoas se reconhecerem em referência às suas práticas de sexualidade com base na oposição masculino/feminino, heterossexual/homossexual e na hierarquia entre esses pares. É ela também que possibilita às pessoas compreenderem a si mesmas a partir de representações identitárias substantivadas a partir de modelos e normas definidos a priori.

Dessa forma, questionam-se as possibilidades de desconstrução das matrizes identitárias concomitantemente ao deslocamento de sentidos a elas agregados, principalmente no que diz respeito às extensões que elas abarcam, ou seja: problematiza-se a substantivação da subjetividade em identidade como necessária e intrínseca à elaboração do psiquismo, bem como se problematiza a necessidade de uma subjetividade substantivada para o exercício e a efetivação do movimento e da ação sobre a realidade. Perguntamos: quais as possibilidades de deslocar o sentido de que a substantivação da subjetividade em identidade configura a única possibilidade para a elaboração psíquica? Qual a possibilidade de problematizar a concepção da ação como necessariamente sobreposta à lógica linear, causal, binária e disjuntiva que separa ativo e passivo, sujeito e objeto? Entendemos que essas questões são importantes, pois questionar os binarismos e as disjunções que norteiam a metafísica da presença e a substantivação da subjetividade e da realidade pode oferecer novos olhares às brechas postas pela diferença e pelo outro que entremeiam as teorias e práticas psicológicas e políticas.

Ao problematizar os binarismos, as disjunções e criticar a estrutura hierárquica, Derrida propõe a experiência de desconstrução a partir de movimentos de espaçamento, em que há a impossibilidade de reduzir "a cadeia a um de seus elos ou de aí privilegiar absolutamente um - ou outro" (2001, p. 106). Com essa atitude, o autor questiona não somente o significado como elemento que carregaria uma dimensão transcendental do signo mas também desconsidera o signo como portador de uma pretensa unidade natural. Questiona, portanto, o logos do signo, do significado vinculado de forma linear e direta ao significante, explicitando que os significantes só são compreensíveis a partir de uma cadeia que os une e estabiliza, em um jogo de referências em que um significante depende do seu anterior e do seu posterior, em uma sucessão infinita de remessas.

Nesse movimento de deslocamento contínuo, nesse jogo de diferimento, espaçamento e remetimento, há a produção de diferenças que escapam à oposição binária e disjuntiva da metafísica, na medida em que não instituem novas oposições, mas propõem um permanente deslocar-se, uma produção de diferir que se denominará a própria différance. Se a différance implica, então, o deslocamento da diferença para um pensamento que não se refere a uma origem, "desconstuir é de certo modo resistir à tirania do Um, do logos, da metafísica (ocidental) na própria língua em que é enunciada, com a ajuda do próprio material deslocado, movido com fins de reconstruções cambiantes" (Derrida \& Roudinesco, 2004, p. 9). 
2 Para Derrida (2008), o texto não se limita à escritura, mas refere-se a um tecido, a uma cadeia de signos na qual as diferenças aparecem entre seus elementos, sendo expressas nas diferentes formas de linguagem.
A perspectiva da desconstrução pode, portanto, ancorar a proposta de problematizar a disjunção e a lógica falogocêntrica que sustentam os atributos designados às mulheres e aos homens (natureza e cultura, razão e afeto, ativo e passivo, dentre outros), problematizando binarismos que sustentam o par feminino e masculino; também torna possível problematizar a perspectiva da ação dissociada entre ativo e passivo e o conceito de que a ação remete necessariamente ao sujeito ativo e substantivado que age sobre a realidade passiva e considerada objeto. Para tanto, a desconstrução demanda trabalhar o discurso e as práticas que as pessoas constroem e experimentam em seu cotidiano. Nesse sentido, nas reflexões que realiza em "corpos que pesam", Butler (2002, p. 154) destaca que a performatividade, como "prática reiterativa e citacional pela qual o discurso produz os efeitos que ele nomeia", imprime aos corpos não só definições sobre ser homem ou ser mulher, mas também, junto a ela, as demais qualificações e sentidos atribuídos ao masculino e ao feminino.

A ideia da performatividade em Butler advém do conceito de atos de fala, de Austin (1976), que parte da compreensão de que "todos os enunciados são performativos, e, portanto, agem, operam" (Pinto, 2007, p. 9), engendrando possibilidades de construção do psiquismo, visto que "a performatividade é a capacidade de ação operada pelo ato de fala na sua materialidade plena - sonora e corporal" (p. 12). Nesse sentido, destaca Pinto que,

se assumirmos a performatividade como o que obriga o sujeito a se constituir em processo, a identidade de falante é também performativa, ou seja, não existe senão na prática e na história de sua própria exibição - e é por isso mesmo sempre múltipla, fragmentada e repetível (2007, p. 16)

Segundo essa concepção, não mais referenciada nos pressupostos de sujeito e de subjetividade como totalidades substantivadas, mas apoiada nos pressupostos de efeitos de subjetivação e de expressões de subjetividade, não há, portanto, a necessidade da presença do sujeito. A estratégia da desconstrução, desse modo, abandona o intento da tradição histórica e filosófica ocidental da busca por uma origem, uma presença e substância, capazes de explicitar o fundamento, a determinação e o movimento primordial de todo o sentido e do conceito que supostamente o traduziria. Trata-se do esforço de permanecer em um jogo em que nenhum dos polos opositivos do binarismo é idealizado e subjuga o outro, porém mantendo-o em um constante remetimento a ambos, em um jogo de nem/ nem.

Nas palavras de Rodrigues (2009, p. 52), a leitura desconstrutiva serve a dois propósitos: “1) mostrar que a desconstrução é algo que acontece no interior dos textos ${ }^{2}$ e 2) discutir como, mesmo na tradição, aparece essa oscilação - a dupla exclusão, que seria esse jogo do nem/nem e a participação, ou seja, a possibilidade de ser isto e aquilo ao mesmo tempo". Para Continentino (2006, p. 17), "tais são os indecidíveis, ou seja, nem palavras, nem conceitos, mas o que Derrida chama de quase-conceitos, pois eles não obedecem à lógica opositiva dos universais, na medida em que se voltam para uma alteridade radical, sem pólo de oposição".

Os indecidíveis possibilitam, assim, problematizar as oposições que percorrem o texto, articulando-se com a desconstrução na medida em que esta se inicia pela evidência das contradições e paradoxos do texto. A prática do nem/nem da indecidibilidade remete à noção de alteridade, "de um outro que sempre se faz demonstrar nesse espaçamento, nesses intervalos, nessa distância que se abre entre" (Rodrigues, 2009, p. 51). 
Segundo a perspectiva da desconstrução derridiana, é possível problematizar os sentidos atribuídos aos pares binários bem como às matrizes identitárias como referências que engendram tanto o enunciado da subjetividade como dos sentidos do masculino e do feminino, a partir da compreensão de que não existe princípio, fundamento ou conceito que seja anterior ou esteja fora do jogo de diferenças. Partindo desse referencial, é possível diferir, adiar, prorrogar os sentidos atribuídos aos conceitos, em que "a identidade fixa é substituída pelos efeitos de um processo contínuo de deslocamento" (Rodrigues, 2009, p. 41).

Finalmente, é importante destacar que a estratégia da desconstrução, tendo em vista a crítica direcionada para a idealização do universal e a queda do singular, privilegia uma referência à alteridade, a uma heterogeneidade e a "uma certa inscrição do mesmo, que não é o idêntico, como différance" (Derrida \& Roudinesco, 2004, p. 34). A crítica à identidade realizada por Derrida, contudo, não corresponde "a uma abdicação quase niilista diante da questão ético-político-jurídica da Justiça e diante da oposição do justo ao injusto" (Derrida, 2007, p. 36).

No pensamento da desconstrução, a busca pela Justiça e as reivindicações políticas serão endereçadas

a singularidades, à singularidade do outro, apesar ou mesmo em razão de sua pretensão à universalidade. Por conseguinte, nunca ceder a esse respeito, manter sempre vivo um questionamento sobre a origem, os fundamentos e os limites de nosso aparelho conceitual, teórico ou normativo em torno da Justiça (...) (Derrida, 2007, p. 37)

Derrida explicita, assim, que a desconstrução está comprometida e empenhada com a Justiça na medida em que a entende como uma experiência de alteridade absoluta, que excede o cálculo e que deve ser reiventada a cada acontecimento, a cada novo caso. O gesto desconstrutor, portanto, envolve o fato de que a experiência da Justiça e da política deverá inevitavelmente enfrentar a condição do incalculável, endereçando-se ao singular.

\section{Outras considerações}

Neste trabalho, partimos do pressuposto de que os sentidos que as pessoas elaboram sobre si e sobre os outros se articulam às suas experiências calcadas em referências universais e singulares. Os atravessamentos entre a cultura, a história e as experiências configuram a constituição de sujeitos marcados por pressupostos binários, hierárquicos e heteronormativos, definidores dos parâmetros das matrizes identitárias que remetem às figuras do homossexual e do heterossexual, do sexo e do gênero, do jovem e do velho, do ativo e do passivo, do branco e do negro, dentre outras. Entretanto, as experiências das pessoas questionam as matrizes identitárias e o pressuposto universal que as anima. Assim, essas experiências estão cercadas de embates, em decorrência, por um lado, da sua inserção na rede social ocidental e moderna alinhada ao pensamento hegemônico falogocêntrico apoiado no logos, no falo e no universal. Por outro lado, essas experiências encontram-se atravessadas pela différance, por indecidíveis e pelo outro, dirigindo-se aos espaçamentos e ao nem/nem que também configuram a elaboração subjetiva e embaralham as representações identitárias calcadas nas referências binárias e disjuntivas. Dessa forma, entendemos que desconstruir a relação unívoca, linear e causal entre matrizes identitárias, subjetividade substantivada e ação sobre o real pode contribuir com as práticas psicológicas e políticas, na medida em que se explicita o trabalho de reiteração da metafísica da presença envolvido nessa relação.

Não obstante, conforme afirma Derrida, não há sentido em abandonar os conceitos 
da metafísica para abalar essa área do conhecimento, tendo em vista que não dispomos de linguagem que seja estranha a essa história. Desse modo, "não podemos enunciar nenhuma proposição destruidora que não se tenha já visto obrigada a escorregar para a forma, para a lógica e para as postulações implícitas daquilo mesmo que gostaria de contestar" (2008, p. 410).

Assim sendo, ressalta-se que problematizar o sujeito constituído como substância e presença e relevar as possibilidades do devir, bem como questionar os binarismos, não significa esquecer o fato de que a constituição psíquica acontece nessa situação, ou seja, somos constituídos e nos constituímos no tempo social e histórico que produz tanto a possibilidade da subjetividade que advém quanto da subjetividade sujeitada. Em outras palavras, não se trata de negar a tradição filosófica ocidental, mas de realizar um questionamento dos limites de uma filosofia da representação, binária e hierárquica, e de problematizar as incidências dessa filosofia nas práticas psicológicas e políticas. 


\section{Mériti de Souza}

Doutora em Psicologia Clínica - PUC-SP. Pós Doutorado no CES - Centro de Estudos Sociais - da Universidade de Coimbra. Professora no Programa de Pós-Graduação em Psicologia da Universidade Federal de Santa Catarina, SC - Brasil.

E-mail:meritidesouza@yahoo.com

\section{Fabíola Langaro}

Psicóloga. Mestre pelo Programa de Pós-Graduação em Psicologia da Universidade Federal de Santa Catarina. Bolsista do Programa FUMDES, SC - Brasil.

E-mail: flangaro@hotmail.com

Endereço para envio de correspondência:

Rua Padova, 44, apto 106 Bairro Córrego Grande, Florianópolis - SC - Brasil. CEP: 88037-640.

Recebido 4/1/2011, Aprovado 16/5/2011. 


\section{Referências}

Austin, J. L. (1976). How to do things with words (2a. ed.). Oxford: Oxford University Press.

Bachelard, G. (1996). A formação do espírito científico. Rio de Janeiro: Contraponto.

Bobbio, N., Matteucci, N., \& Pasquino, G. (1986a). Dicionário de política. Brasília, DF: Universidade de Brasília.

Bobbio, N. (1986b). O futuro da democracia: uma defesa das regras do jogo. Rio de Janeiro: Paz e Terra.

Burdeau, G. O liberalismo. (s/d). Portugal: Publicações EuropaAmérica.

Butler, J. (2002). Cuerpos que importan: Sobre los límites materiales y discursivos del "sexo". Buenos Aires: Paidós.

Butler, J. (2008). Problemas de gênero - feminismo e subversão da identidade. Rio de Janeiro: Civilização Brasileira.

Chauí, M. (2000). Convite à filosofia. São Paulo: Editora Ática.

Continentino, A. M. A. (2006). A alteridade no pensamento de Jacques Derrida: escritura, meio-luto, aporia. Tese de doutorado em Filosofia - Pontifícia Universidade Católica do Rio de Janeiro, Rio de Janeiro.

Derrida, J. (2001). Posições. Belo Horizonte: Autêntica.

Derrida, J. (2007). Força de lei: o fundamento místico da autoridade. São Paulo: WMF/Martins Fontes.

Derrida, J. (2008). Gramatologia. São Paulo: Perspectiva.

Derrida, J. (2009). Escritura e diferença. São Paulo: Perspectiva.

Derrida, J. (2004, 15 de agosto). [Entrevista a Evando Nascimento, no Caderno Mais]. Folha de São Paulo.

Derrida, J., \& Roudinesco, E. (2004). De que amanhã: diálogo. Rio de Janeiro: Jorge Zahar.
Figueiredo, L. C. (1992). A invenção do psicológico: quatro séculos de subjetivação. São Paulo: Escuta.

Foucault, M. (1990). Microfísica do poder. Rio de Janeiro: Edições Graal.

Foucault, M. (1999). As palavras e as coisas. Uma arqueologia das ciências humanas. São Paulo: Martins Fontes.

Freire Costa, J. (1998). A construção cultural da diferença dos sexos. Sexualidade, Gênero e Sociedade, 2(3), 3-8. Recuperado em 25 de março de 2010, de http://jfreirecosta. sites.uol.com.br/artigos/artigos_html/construcao cultural.html

Morin, E. (2005). O método III: o conhecimento do conhecimento. Porto Alegre: Sulina.

Pinto, J. P. (2007). Conexões teóricas entre performatividade, corpo e identidades. DELTA, 23(1), 1-26.

Rodrigues, C. (2009). Coreografias do feminino. Florianópolis, SC: Editora Mulheres.

Silva, T. T. (2008). A produção social da identidade e da diferença. In T. T. Silva (Org.), Identidade e diferença: a perspectiva dos estudos culturais (8a. ed., pp. 73-102). Petrópolis, RJ: Vozes.

Souza, M. (2007). Efeitos de subjetivação, práticas sociais e emancipação social: reflexões a partir de práticas psicológicas em contextos escolarizados. (pp. 1-32, Coleção Oficinas do Ces - Universidade de Coimbra, 2006).

Souza, M. (2006). Narrativas, conhecimento e homem simbólico: entrelaçamentos entre saberes e fazeres. Mal-estar e Subjetividade, 6(1), 137-161.

Sousa Santos, B. (2002). A crítica da razão indolente. São Paulo: Cortez.

Sousa Santos, B. (2003). Um discurso sobre as ciências. Portugal: Edições Afrontamento. 